\title{
Monitoring clinical and microbiological evolution of a cystic fibrosis patient over 26 years: experience of a Brazilian CF Centre
}

Cassiana da Costa Ferreira Leite ${ }^{1 \dagger}$, Tania Wrobel Folescu ${ }^{2+}$, Mônica de Cássia Firmida ${ }^{3}$, Renata Wrobel Folescu Cohen², Robson Souza Leão ${ }^{1}$, Flávia Alvim Dutra de Freitas ${ }^{4}$, Rodolpho Mattos Albano ${ }^{4}$, Claudia Henrique da Costa $^{3}$ and Elizabeth Andrade Marques ${ }^{1,5^{*}}$

\begin{abstract}
Background: Burkholderia cepacia complex is a group of opportunistic pathogens in cystic fibrosis (CF) patients believed to be associated with poor prognosis and patient-to-patient transmissibility. Little is known about clinical outcomes after B. vietnamiensis chronic colonization/infection.

Case presentation: A 33 yo male patient had diagnosis of CF by 7 yo, after recurrent pneumonia during infancy and lobectomy (left upper lobe) at 6 yo. Burkholderia cepacia complex (Bcc) was first isolated by 13 yo, and the patient fulfilled the criteria for chronic colonization by 15 yo. In the following 16 years (1997-2013), there was intermittent isolation of $P$. aeruginosa and continuous isolation of $B c c$, identified as $B$. vietnamiensis. There was clinical and laboratorial stability for 16 years with annual rate of decline in forced expiratory volume in $1 \mathrm{~s}$ (FEV1) and forced vital capacity (FVC) of 1.61 and 1.35\%, respectively. From 2013 to 2015, there was significant clinical and lung function deterioration: annual rate of decline in FEV1 and FVC was 3 and 4.1\%, respectively while body mass index decreased from 18.1 to 17.1. Episodes of hemoptysis and respiratory exacerbations (with hospital admissions) became more frequent. CF related diabetes was diagnosed (fasting glycemia: $116 \mathrm{mg} / \mathrm{dL}$, oral glucose tolerance test: $305 \mathrm{mg} / \mathrm{dL}$ ). Because of the severity of the disease in the last years, in addition to traditional microbiological surveillance, microbiome analysis by next generation sequencing (NGS) was performed on respiratory secretions. The NGS showed that $97 \%$ of the sequencing data were attributed to genus Burkholderia.

Conclusions: We report the case of a 33-year-old male CF patient known to have chronic infection with B. vietnamiensis who remained clinically stable for 16 years and presented recent clinical and laboratorial deterioration. Microbiome analysis of respiratory secretions was performed in 3 samples collected in 2014-2015. Clinical deterioration overlapped with cystic fibrosis-related diabetes and microbiome composition revealed no significant differences when compared microbiome results to culture dependent methods.
\end{abstract}

Keywords: Burkholderia vietnamiensis, Burkholderia cepacia complex, Cystic fibrosis, Microbiome, Chronic lung disease, Cystic fibrosis-related diabetes

\footnotetext{
* Correspondence: marbe@uerj.br

${ }^{\dagger}$ Equal contributors

'Departamento de Microbiologia, Imunologia e Parasitologia, Faculdade de Ciências Médicas, Universidade do Estado do Rio de Janeiro, Rio de Janeiro, Brazil

${ }^{5}$ Departamento de Microbiologia, Imunologia e Parasitologia, Faculdade de Ciências Médicas, Universidade do Estado do Rio de Janeiro, Brazil Av. 28 de setembro 87, Fundos, Terceiro andar- Vila Isabel, Rio de Janeiro, RJ, Brazil Full list of author information is available at the end of the article
} 


\section{Background}

Burkholderia cepacia complex (Bcc) is a group of opportunistic pathogens, with at least 20 distinct genomovars/ species [1], believed to be associated with poor prognosis and patient-to-patient transmissibility in cystic fibrosis (CF). Burkholderia cenocepacia and B. multivorans are more prevalent, but in Brazil B. vietnamiensis was identified as the second most prevalent species in this species complex in patients attending a reference center [2].

In comparison with $B$. cenocepacia, the clinical significance of a chronic colonization of the airways by the other Bcc species is much less clear. The chronic airway colonization by $B$. multivorans, for example, has not been associated with an increased mortality or accelerated decline in the lung function when compared to chronic colonization with Pseudomonas aeruginosa [3-5].

Based on these considerations, we describe the 26 year follow-up of a CF patient colonized with $B$. vietnamiensis who remained clinically stable for 16 years and experienced progressive progressive clinical worsening in the last 3 years. This case raised several issues regarding factors influencing clinical deterioration and the possible impact of changes in lung microbiome composition.

\section{Case presentation}

A 33-year-old male patient had diagnosis of CF by 7 yo attested by two positive sweat chloride tests $(136.6 \mathrm{~m} \mathrm{Eq} / \mathrm{L}$ and $129.8 \mathrm{mEq} / \mathrm{L}$ ) and sequence analysis of the gene CFTR (homozygosity for G85E). Before this time, he had recurrent pneumonia during infancy and was submitted to lobectomy (left upper lobe) at 6 yo.

After diagnosis, he presented chronic sinopulmonary disease characterized by chronic cough, recurrent wheezing and gastrointestinal impairment with pancreatic insufficiency and failure to thrive. Pseudomonas aeruginosa was first isolated in sputum samples by 8 yo (1990). Chronic colonization by mucoid and non mucoid $P$. aeruginosa was recognized at 10 yo (1992). Three years later (13 yo - 1995),
Bcc was first isolated, and the patient fulfilled the criteria for Bcc chronic colonization [6] by 15 yo. In the following 16 years (1997-2013), there was intermittent isolation of $P$. aeruginosa and continuous isolation of Bcc, identified as $B$. vietnamiensis [7] (Fig. 1). Clinical data were registered during each visit at the CF center, including body mass index (BMI) and spirometric measurements (\% predicted), i.e. forced expiratory volume in $1 \mathrm{~s}\left(\mathrm{FEV}_{1}\right)$ and forced vital capacity (FVC). In order to study the trend of respiratory function parameters over time, it was calculated the annual rate of decline by linear regression.

At the moment of chronic $P$. aeruginosa colonization, the patient presented: $\mathrm{BMI}, 18 ; \mathrm{FEV}_{1}, 72 \%$; and $\mathrm{FVC}$, $87 \%$. At the moment of the first isolation of Bcc, BMI, $\mathrm{FEV}_{1}$ and FVC were of 16,70 and $85 \%$, respectively. These values changed to $16.91,64$ and $80 \%$ for BMI, $\mathrm{FEV}_{1}$ and FVC when chronic Bcc isolation was identified. From 1995 to 2013, the patient remained clinically stable, using regular medication for CF and inhaled antibiotics for Pseudomonas aeruginosa chronic colonization (tobramycin alternate months). He required on average one hospital admission per year due to respiratory exacerbation and, during this period, presented BMI:16.9-18.1, with $\mathrm{FEV}_{1}(\%)$ and $\mathrm{FVC}(\%)$ annual rate of decline of 1.61 and $1.35 \%$, respectively.

However, from 2013 to 2015, there was significant clinical and lung function deterioration: $\mathrm{FEV}_{1} \%$ and FVC\% annual rate of decline was 3 and $4.1 \%$ respectively while BMI decreased from 18.1 to 17.1. He presented glucose intolerance in 2013, with lung function close to this moment showing $\mathrm{FEV}_{1}$ of $25.1 \%$ and FVC of $39.1 \%$. Since June 2014, he started episodes of hemoptysis and required more frequent hospital admissions due to respiratory exacerbations. CF related diabetes (CFRD) was diagnosed in 2014 (fasting glycemia: $116 \mathrm{mg} / \mathrm{dL}$, oral glucose tolerance test: $305 \mathrm{mg} / \mathrm{dL}$ ). The patient was on regular use of alpha dornase, short and long action inhaled bronchodilators, inhaled corticosteroids, azithromycin,

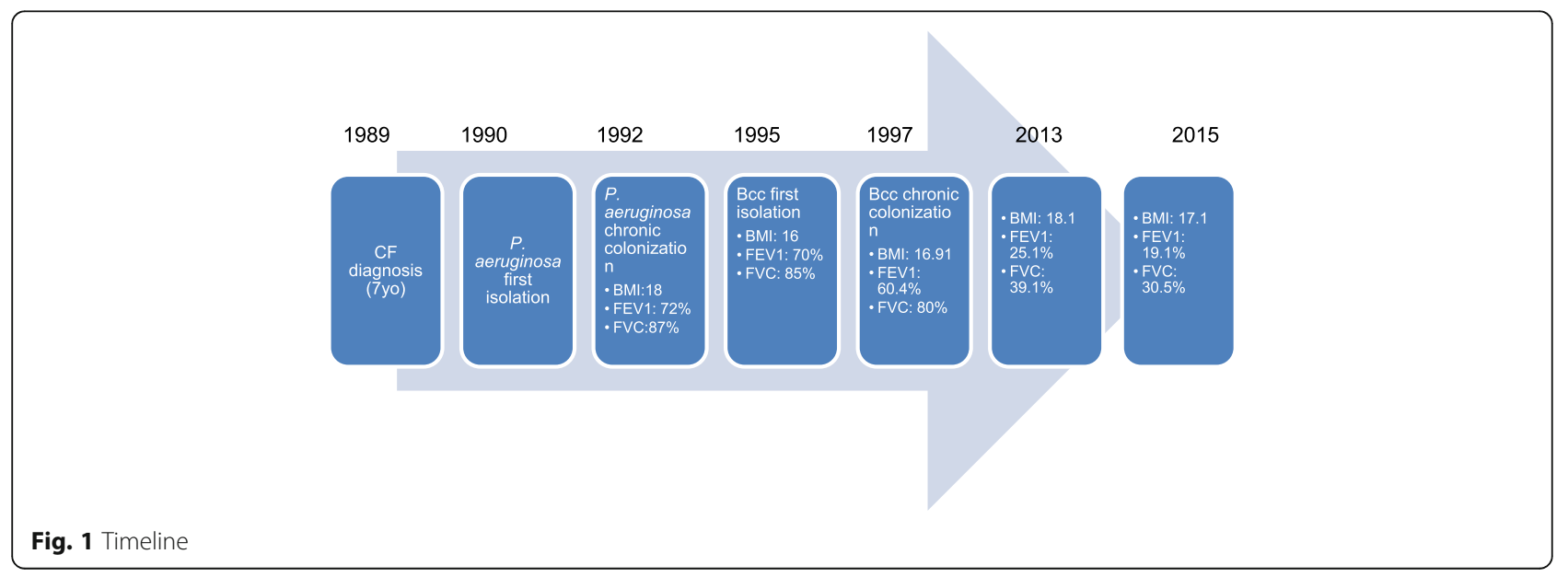




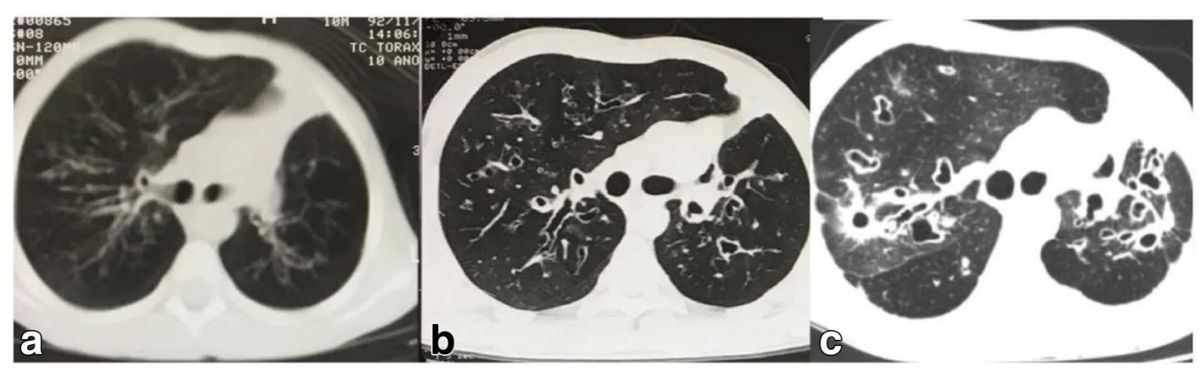

Fig. 2 High resolution computed tomography images: 1992 (a); 2000 (b); 2015 (c)

pancreatic enzymes and insulin replacement. By this time, the patient showed poor adherence to treatment and received oral ciprofloxacin for 14 days (June, 2014) and IV meropenem (September, 2014) during hospitalization. In the following year (2015), he was admitted in hospital due to respiratory exacerbation twice.

Available high resolution computed tomography (HRCT) evaluation through modified Bhalla score [8] presented the following total score: 9 in 1992, 17 in 2000 and 25 in 2015. The last HRCT scan (2015) highlighted the increase in severity of bronchiectasis, thickening of bronchial walls, mosaic pattern, air trapping and diffuse ground glass images (Fig. 2).

Because of the severity of the disease in the last years (2014-2015), in addition to traditional microbiological surveillance, microbiome analysis by next generation sequencing was performed on respiratory secretions at three clinical visits (June 27, 2014; September 26, 2014; and January 09, 2015). Aerobic cultures from these sputum samples presented two main microorganisms related to lung infection/colonization in the CF patient: $P$. aeruginosa and Bcc (identified as B. vietnamiensis by polymerase chain reaction (PCR) and sequencing of the recA gene). The first two samples presented Bcc and $P$. aeruginosa (non mucoid type), while $P$. aeruginosa (non mucoid type) and Bcc with both mucoid and non mucoid morphotypes were identified in the third sample.

Microbiome analysis of sputum samples was performed by sequencing the $\mathrm{V} 4$ region of the $16 \mathrm{~S}$ rRNA gene in an Illumina MiSeq instrument [9]. The following data was obtained from the three samples collected from June 2014 to January 2015 (6 months period): $97 \%$ of the sequencing data were attributed to genus Burkholderia (98.7, 98.6 and 92.3\% of each sputum sample, respectively). Although Burkholderia was remarkably predominant, other genera related to CF lung infections were also found: Pseudomonas (0.71\%), Rothia (1.65\%), Staphylococcus (0.07\%), Haemophilus (0.29\%), Ralstonia (0.002\%) (Table 1).

\section{Discussion and conclusions}

Despite advances in Bcc taxonomy, predicting prognosis in infected CF patients is challenging. Previous studies

Table 1 Presence in aerobic cultures and microbiome analysis of collected sputum samples

\begin{tabular}{|c|c|c|c|c|c|c|}
\hline & \multicolumn{2}{|l|}{ June 2014} & \multicolumn{2}{|l|}{ September 2014} & \multicolumn{2}{|l|}{ January 2015} \\
\hline & Presence in Culture & $\begin{array}{l}\text { Microbiome } \\
\text { Analysis }\end{array}$ & Presence in Culture & $\begin{array}{l}\text { Microbiome } \\
\text { Analysis }\end{array}$ & Presence in Culture & $\begin{array}{l}\text { Microbiome } \\
\text { Analysis }\end{array}$ \\
\hline Burkholderia & Yes & $98.7 \%^{a}$ & Yes & $98.6 \%$ & Yes & $92.6 \%$ \\
\hline Rothia & No & $0.53 \%$ & No & $0.67 \%$ & No & $4.6 \%$ \\
\hline Pseudomonas & Yes & $0.57 \%$ & Yes & $0.47 \%$ & Yes & $1.27 \%$ \\
\hline $\begin{array}{l}\text { Unclassified } \\
\text { Enterobacteriaceae }\end{array}$ & No & $0 \%$ & No & $0 \%$ & No & $0.04 \%$ \\
\hline $\begin{array}{l}\text { Unlcassified } \\
\text { Burkholderiaceae }\end{array}$ & - & $0 \%$ & - & $0.02 \%$ & - & $0 \%$ \\
\hline $\begin{array}{l}\text { Unclassified } \\
\text { Burkholderiales }\end{array}$ & - & $0 \%$ & - & $0 \%$ & - & $0.25 \%$ \\
\hline Ralstonia & No & $0 \%$ & No & $0.006 \%$ & No & $0 \%$ \\
\hline $\begin{array}{l}\text { Unclassified } \\
\text { Alcaligenaceae }\end{array}$ & - & $0 \%$ & - & $0.006 \%$ & - & $0.02 \%$ \\
\hline Haemophilus & No & $0 \%$ & No & $0 \%$ & No & $1.12 \%$ \\
\hline Staphylococcus & No & $0.08 \%$ & No & $0.04 \%$ & No & $0.13 \%$ \\
\hline
\end{tabular}


have shown that CF patients chronically colonized with Bcc present greater deterioration of lung function, require frequent antibiotic therapy and display increased mortality when compared to patients colonized with $P$. aeruginosa $[10,11]$. However, no studies have described the clinical evolution of CF patients chronically colonized with $B$. vietnamiensis. In our case, a CF patient chronically colonized with $B$. vietnamiensis remained in stable conditions for over than 16 years, with FEV1 and FVC annual rate of decline within the expected range, and experienced significant clinical deterioration in the last 3 years: he presented hemoptysis, lung function decline and more exacerbations, despite regular prescription of maintenance therapy.

For CF lung disease, risk factors associated with $\mathrm{FEV}_{1}$ decline include (but are not limited to) young age, high lung function, female gender, modifier genes, pancreatic insufficiency, poor nutritional status, viral respiratory infections, colonization with $P$. aeruginosa and Bcc, and diabetes mellitus [12]. Mean rate of $\mathrm{FEV}_{1} \%$ predicted decline in CF patients chronically colonized with Bcc was significantly higher than expected in all ages [6], although there was no correlation to Bcc species. In our report, chronic Bcc colonization and clinical stability had been present over a long period. However, the lung function steadly declined in the last 3 years, coinciding with the moment of CFRD diagnosis. CFRD is an important cause of morbidity in CF since insulin insufficiency and hyperglycemia, promoting oxidative stress, inflammation and infection, negatively affect CF lung disease. Nutritional status and pulmonary function begin to decline in CF patients several years before the actual diagnosis of CFRD, when minimal hyperglycemia is present. Abnormal glucose tolerance relates to insulin insufficiency and insulin resistance [13]. Since insulin is an anabolic hormone, insulin insufficiency may reduce inspiratory and diaphragm muscle function, further worsening lung function [14]. The deterioration of the reported CF patient lung function overlaps with CFRD diagnosis and, in fact, hyperglycemia may have started before and contributed to clinical deterioration as well as other factors such as poor adherence to treatment. In addition to all clinical factors that might justify clinical deterioration, culture-independent techniques could be of use to allow a greater understanding of the respiratory microbiome in this CF patient. This analysis confirmed that Burkholderia was the predominant genus. Pseudomonas appeared in low relative abundance in the three sputum samples, suggesting that the status of $P$. aeruginosa on routine microbiological cultures, usually referred as the major CF pathogen, could be overstated. In conclusion, clinical factors such as CFRD and poor adherence to treatment may have contributed to lung function deterioration. Nevertheless, although less frequent than the bacterial infections, we cannot exclude the fungal and viral respiratory infections as a risk factor associated with $\mathrm{FEV}_{1}$ decline. In addition, despite the small number of samples used for culture-independent analysis which limits our understanding of the lung microbiome of this patient, there was a good agreement with sputum cultures that showed chronic colonization with Bcc.

\section{Abbreviations \\ Bcc: Burkholderia cepacia complex; BMI: Body mass index; CF: Cystic fibrosis; CFRD: CF-related diabetes; FEV1: Forced expiratory volume in $1 \mathrm{~s}$; \\ FVC: Forced vital capacity; HRCT: High-resolution computed tomography; PCR: Polymerase chain reaction}

\section{Acknowledgements}

We would like to thank Erica Santos for her help in microbiological analysis of respiratory secretions.

Availability of data and material

All data generated or analysed during this study are included in this published article.

Funding

Grants: FAPERJ-Fundação Carlos Chagas Filho de Amparo à Pesquisa do Estado do Rio de Janeiro-E-26/110.742/2013.

Authors' contributions

TF, EM and RA conceived the study, its design and coordination. TF, MF, RC and $C C$ were involved in the management of the case. $C L, R L$ and FF carried out the sequencing experiments and bioinformatic analyses. RL and RA participated in the draft of the manuscript. All authors read and approved the final version of this manuscript.

Ethics approval and consent to participate

Approval was obtained from the ethics committee: Plataforma Brasil CAAE-026761.2.1.0000.5269.

Consent for publication

Consent from the patient was obtained to include individual personal data in any form.

\section{Competing interests}

The authors declare that they have no competing interests.

\section{Publisher's Note}

Springer Nature remains neutral with regard to jurisdictional claims in published maps and institutional affiliations.

\section{Author details}

'Departamento de Microbiologia, Imunologia e Parasitologia, Faculdade de Ciências Médicas, Universidade do Estado do Rio de Janeiro, Rio de Janeiro, Brazil. ${ }^{2}$ Instituto Nacional de Saúde da Mulher da Criança e do Adolescente Fernandes Figueira, Fundação Oswaldo Cruz, Rio de Janeiro, Brazil. ${ }^{3}$ Departamento de Doenças do Tórax, Faculdade de Ciências Médicas, Universidade do Estado do Rio de Janeiro, Rio de Janeiro, Brazil. ${ }^{4}$ Departamento de Bioquímica, Instituto de Biologia Roberto Alcântara Gomes, Universidade do Estado do Rio de Janeiro, Rio de Janeiro, Brazil. ${ }^{5}$ Departamento de Microbiologia, Imunologia e Parasitologia, Faculdade de Ciências Médicas, Universidade do Estado do Rio de Janeiro, Brazil Av. 28 de setembro 87, Fundos, Terceiro andar-Vila Isabel, Rio de Janeiro, RJ, Brazil.

Received: 27 January 2017 Accepted: 29 June 2017

Published online: 14 July 2017

\section{References}

1. Smet BD, Mayo M, Peeters C, Zlosnik JEA, Spilker T, Hird TJ, LiPuma JL, Kidd TJ, Kaestli M, Ginther JL, Wagner DM, Keim P, Bell SC, Jacobs JA, Currie BJ, Vandamme P. Burkholderia stagnalis sp. nov. and Burkholderia territorii sp. 
nov., two novel Burkholderia cepacia complex species from environmental and human sources. Int J Syst Bacteriol. 2015;65:2265-71.

2. Vicenzi FJ, Pillonetto M, Souza HAPHM, Palmeiro JK, Riedi CA, Rosario-Filho NA, Dalla-Costa LM. Polyphasic characterisation of Burkholderia cepacia complex species isolated from children with cystic fibrosis. Mem Inst Oswaldo Cruz. 2016;111(1):37-42.

3. Courtney JM, Dunbar KEA, MC Dowel A, Moore JE, Warke TJ, Stevenson M, Elborn JS. Clinical outcome of Burkholderia cepacia complex in cystic fibrosis adults. J Cyst Fibros. 2004;3:93-8.

4. Jones AM, Dodd ME, Govan JRW, Barcus V, Doherty CJ, Morris J, Webb AK. Burkholderia cenocepacia and Burkholderia multivorans: influence on survival in cystic fibrosis. Thorax. 2004;59:948-51.

5. Kalish LA, Waltz DA, Dovey M, Potter-Bynoe G, McAdam AJ, LiPuma JJ, Gerard C, Goldmann D. Impact of Burkholderia dolosa on lung function and survival in cystic fibrosis. Am J Respir Crit Care Med. 2006;173(4):421-5.

6. Folescu TW, Costa CH, Cohen RWF, Neto OCC, Albano RM, Marques EA. Burkholderia cepacia complex: clinical course in cystic fibrosis patients. BMC Pulm Med. 2015;15:158-63.

7. Carvalho GM, Carvallho AP, Folescu TX, Higa L, Teixeira LM, Plotkowski MC, Merquior VL, Albano RM, Marques EA. Transient isolation of Burkholderia multivorans and Burkholderia cenocepacia from a Brazilian cystic fibrosis patient chronically colonized with Burkholderia vietnamiensis. J Cyst Fibros. 2005;4(4):267-70.

8. Judge EP, Dodd JD, Masterson JB, Gakkagher CG. Pulmonary abnormalities on high-resolution CT demonstrate more rapid decline than FEV1 in adults with cystic fibrosis. Chest. 2006;130(5):1424-32.

9. Caporaso JG, Lauber CL, Walters WA, Berg-Lyons D, Huntley J, Fierer N, Owens SM, Betley J, Fraser L, Bauer M, Gromley N, Gilbert JA, Smith G, Knight R. Ultra- high-throughput microbial community analysis on the Illumina HiSeq amd MiSeq platforms. ISME J. 2012;6(8):1621-4.

10. McCloskey M, McCaughan J, Redmond A, Elborn JS. Clinical outcome after acquisition of Burkholderia cepacia in patients with cystic fibrosis. Ir J Med Sci. 2001;170(1):28-31.

11. Correia S, Nascimento C, Pereira L, Cunha MV, Sá-Correia I, Barreto C. The clinical course of Burkholderia cepacia complex bacteria respiratory infection in cystic fibrosis patients. Rev Port Pneumol. 2008;14(1):5-26.

12. Konstan MW, Morgan WJ, Butler SM, Pasta DJ, Craib ML, Silva SJ, Stokes DC Wohl ME, Wagener JS, Regelmann WE, Johnson CA. Scientific advisory group and the investigators and coordinators of the epidemiologic study of cystic fibrosis. Risk factors for rate of decline in forced expiratory volume in one second in children and adolescents with cystic fibrosis. J Pediatr. 2007:151(2):34-9.

13. Moran A, Becker D, Casella SJ, Gottlieb PA, Kirkman MS, Marshall BC, Slovis B. Epidemiology, pathophysiology, and prognostic implications if cystic fibrosis-related diabetes. Diabetes Care. 2010;33(12):2677-83.

14. Alves CAD, Aguiar RA, Alves ACS, Santana MA. Diabetes mellitus in patients with cystic fibrosis. J Bras Pneumol. 2007;33(2):213-21.

\section{Submit your next manuscript to BioMed Central and we will help you at every step:}

- We accept pre-submission inquiries

- Our selector tool helps you to find the most relevant journal

- We provide round the clock customer support

- Convenient online submission

- Thorough peer review

- Inclusion in PubMed and all major indexing services

- Maximum visibility for your research

Submit your manuscript at www.biomedcentral.com/submit

) Biomed Central 